\title{
The Effect of Nano-Micro Silica Mixture on the Shear Strength of Reinforced Concrete Beams
}

\author{
E. Radwan ${ }^{1}$, A. S. Debaiky ${ }^{2}$, and M. Taha ${ }^{3}$ \\ ${ }^{I}$ Senior Structural Design Engineer-HAMZA ASSOCITES for Engineering Consultant, Cairo, Egypt \\ E-mail: ehab.radwan73@gmail.com \\ ${ }^{2}$ Professor, Civil Engineering Department, Benha University, Benha, Egypt \\ E-mail: ahmed.aldebaiky@bhit.bu.edu.eg \\ ${ }^{3}$ Distinguished Professor \& Chair, Department of Civil, Construction and Environmental Engineering, The University of New Mexico, New Mexico, USA \\ E-mail: $\underline{\text { mrtaha@unm.edu }}$
}

\begin{abstract}
This paper examines the significance of nano silica and micro silica mixture on the shear strength of reinforced concrete beams. The nano and micro silica mixture was used as a partial replacement for Portland cement with different proportions to produce four (4) concrete mixtures. In this research, the tests on fresh concrete mixtures (slump test, density test and air content test) were performed. The compressive strength of concrete mixtures was tested. The shear strength of reinforced concrete beams with and without shear reinforcement is examined. Moreover, the influence of the multi-sized silica mixture on the mechanical characteristics of concrete related to the shear behavior of concrete beams, shear crack width, the inclination angle of shear cracks and deflection were also examined. From test results, the mixture of $2 \%$ nano silica with $8 \%$ micro silica was found to lead to the highest compressive strength, it improve the concrete compressive strength up to $33 \%$ compared with control specimens. The shear strength of the concrete beam incorporating $8 \%$ micro silica and $2 \%$ nano silica mixture was also improved, it increased by $30 \%$ and $59 \%$ for beams with and without steel stirrups, respectively. The significance of nano-micro silica mixture on the concrete contribution to the shear strength of reinforced concrete beams is examined. The nano-micro silica mixture increased concrete contribution to shear strength of reinforced concrete beams up to $17 \%$.
\end{abstract}

Keywords: Shear Strength, Nano-Silica, Micro-Silica, Concrete Beams.

\section{INTRODUCTION}

The concrete is the most important construction material in the world which used within the scope civil works. The cement is considered the main component of the concrete mixture. Every day the concrete is produced in millions cubic meters around the world which need to produce the large quantities of the cement. It is recognized that every ton of cement in the manufacture produces about a ton of carbon dioxide, the carbon dioxide is the main reason to increase the problem of global warming, so the global trend to reduce the production of the cement to reduce the carbon dioxide emitted. It is logical that reducing the cement content in the mixture is partially help to solve this problem. This comes from improving the properties of concrete using pozzolanic materials and other techniques including the use of nano-particles, which leads to increase mechanical properties, which allows either reducing the sections or minimizing the cement content in the same mix to get the same load carrying capacity.

A nanometer is a very small size. It cannot be observed by the eye but can be observed under light or scanning electron microscopes. The reduction in material size from micro to nano leads to a significant change in the material's ability to affect material's physical and mechanical properties [1]. The power of nanomaterials to alter the mechanical properties is attributed to their ability to alter the chemical reaction. Thus, they produce a new nano-modified material with a new set of physical and mechanical characteristics [2].

Pozzolanic materials are a siliceous or alumina siliceous material. When the pozzolanic materials add to the concrete mixture, with the presence of moisture, it chemically reacts with calcium hydroxide $\mathrm{Ca}(\mathrm{OH})_{2}$, also known as $\mathrm{CH}$, to form calcium-silicate-hydrate or (C-S-H) [3]. C-S-H is the primary glue material in concrete. The formation of $\mathrm{C}-\mathrm{S}-\mathrm{H}$ reduces concrete porosity, increases the concrete strength, and improves its durability. Pozzolanic materials are thus added to the cement in the concrete admixture to improve the mechanical properties of concrete. Pozzolanic materials have been used as supplementary cementitious materials in concrete mixtures since the late 1970s [2].

When nano silica particles are added to the concrete mixture, they act as a pozzolanic material and react with $\mathrm{CH}$ to form C-S-H. Figure 1 illustrates the particle size and the specific surface area of the different materials used to produce concrete [4]. The huge specific surface area of nano-size silica particles enhances their chemical activity, as pozzolanic material [4]. Moreover the reduced size of nano particles permits the quantum effects (i.e. quantum sized pores and tunnels) to play a remarkable role in enhancing the cemen-tious materials properties [1,5]. Accordingly, high microstructural density is usually observed in the nano silica modified cementitious materials due to either the nano particle's high pozzolanic reactivity or their pore filling mechanism. Therefore, nano silica particles partial replacement enhances strength and durability of cementitious materials.

Abhilash et al. (2021) [6] studied the effect of nano-silica in concrete. From the experimental program and analysis of results, it is concluded that the addition of nano silica particles in concrete mixtures requires a higher quantity of water or plasticizers to maintain the concrete workability [6]. It is also concluded that nano silica dosage up to 2 to $3 \%$ could improve mechanical and durability properties. This observation could be due to pozzolanic action, filling effect, and pore structure refinement of nano silica [6]. The compressive strength increases as nano silica content increases and the nano silica serves as an activator to promote the process of hydration [6]. However, the strength may be reduced if the content of nano silica particles exceeds $3 \%$ due to its negative effect on concrete workability [6]. 


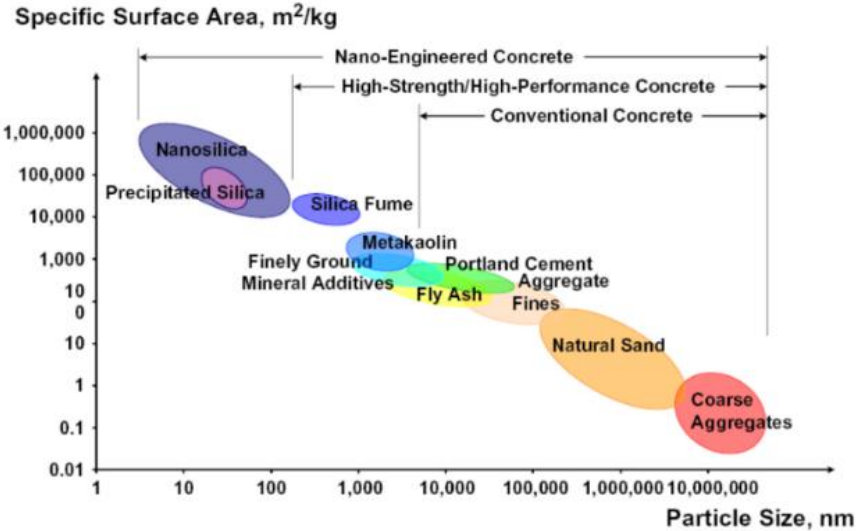

Figure 1. Particle size and specific surface area of the different materials used to produce concrete. [4]

Silva et al. [7] studied the influence of nano particles additions on the structural behavior of reinforced concrete beams in terms of both shear strength and bending moment capacity [7]. Concrete mixtures with additions of either nano silica or aluminum nanoparticles were produced. An experimental program was organized in two sets: i) eight beams tested until shear failure was reached, and ii) eight beams tested until failure in bending was observed [7]. It was concluded that the addition of nanoparticles to the concrete mixtures could lead to a strength increase, both in shear and in bending[7].

During this research, the effect of using nano-micro silica mixture on physical properties and mechanical properties is investigated.

\section{RESEARCH SIGNIFICANCE}

The main objective of this research is to investigate the effect of using nano and micro silica particles on the shear strength of reinforced concrete beams. Our goal is to examine the possible reduction in cement content using nano silica. Reduction in the cement content will help in reduction of the carbon footprint of concrete. The following investigations were performed to achieve these objectives:

- Studying the effect of nano and micro silica particles on the physical properties of fresh concrete.

- Studying the effect of nano and micro silica particles on the compressive strength of concrete.

- Studying the shear behavior of reinforced concrete beams produced using concretes incorporating nano and micro silica.

- Understanding the significance of nano and micro silica particles on the concrete shear contribution in reinforced concrete beams

\section{MATERIALS}

Ordinary portland cement (CEM I $42.5 \mathrm{~N}$ ) compatible with EN 197-1 [8] was used for all concrete specimens. Micro-Silica complying with ASTM C 1240 [9] and Nano-Silica particles, were used as pozzolanic materials. Figures 2 and 3 show the Transmission Electron Microscope (TEM) and X-ray Diffraction (XRD) pattern of Nano Silica sample, respectively, as provided by the manufacturer (HBRC) [10]. Figure 2 indicates that the range of nano particle size is $8-20 \mathrm{~nm}$, and Fig. 3 shows the amorphous nature of NS particles. All concrete specimens used in this experimental investigation were made quartz sand ,as fine aggregate, had less than $3 \%$ of particles finer than $75 \mu \mathrm{m}[11]$.

The fine aggregate used was in the saturated surface dry condition and complied with the limits of ASTM C33 [12]. The fine aggregate used in this experimental investigation passed from $4.75 \mathrm{~mm}$ sieve with fineness modulus $=2.47$, a specific gravity of 2.52, absorption percentage of $1 \%$.

Figure 4 presents the grain size distribution curve of the fine aggregates. The coarse aggregate used in this experimental investigation was dolomite with a maximum nominal size of 20 $\mathrm{mm}$, with a specific gravity of 2.65 .

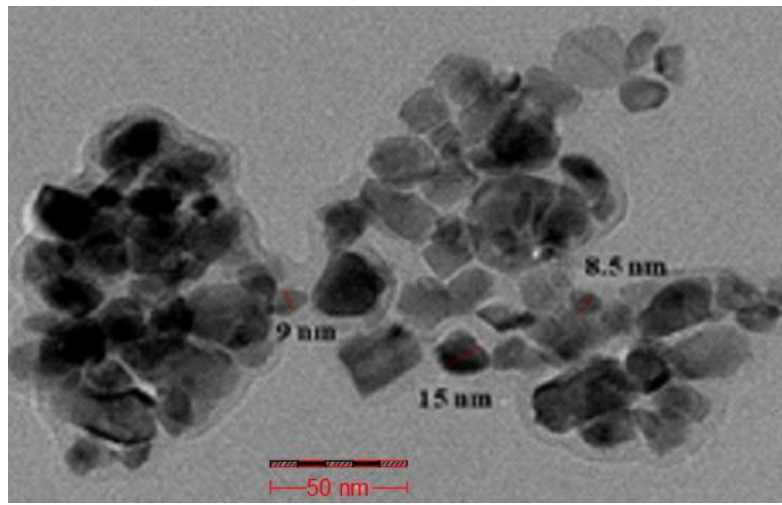

Figure 2: TEM image of Nano-Silica (NS) particles [10].

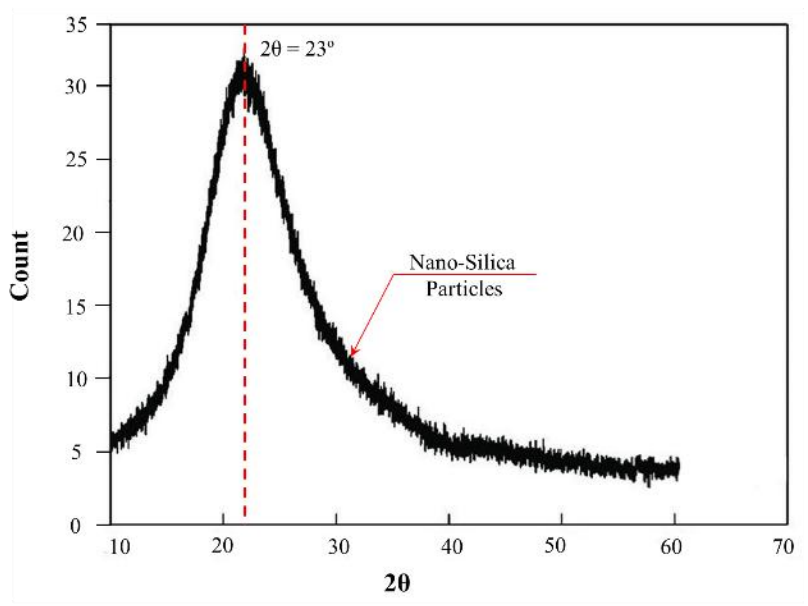

Figure 3. The X-Ray Diffraction of Nano-Silica (NS) particles [10].

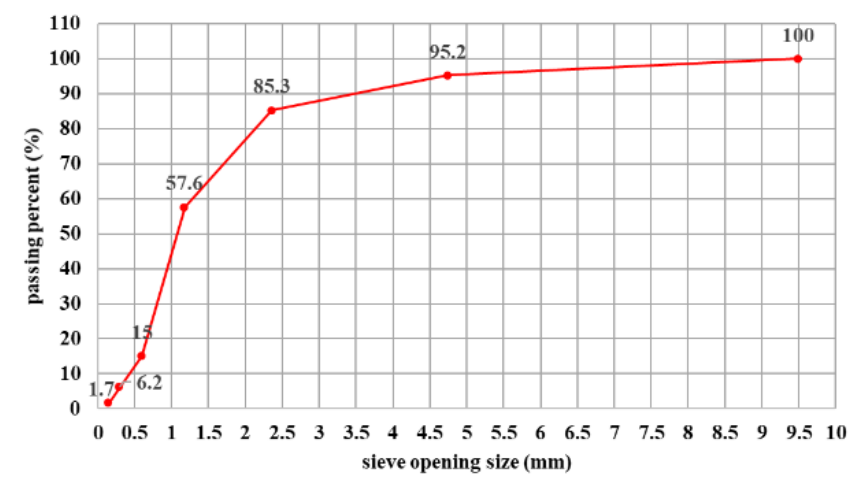

Figure 4. The particle size distribution curve of the fine aggregates. 


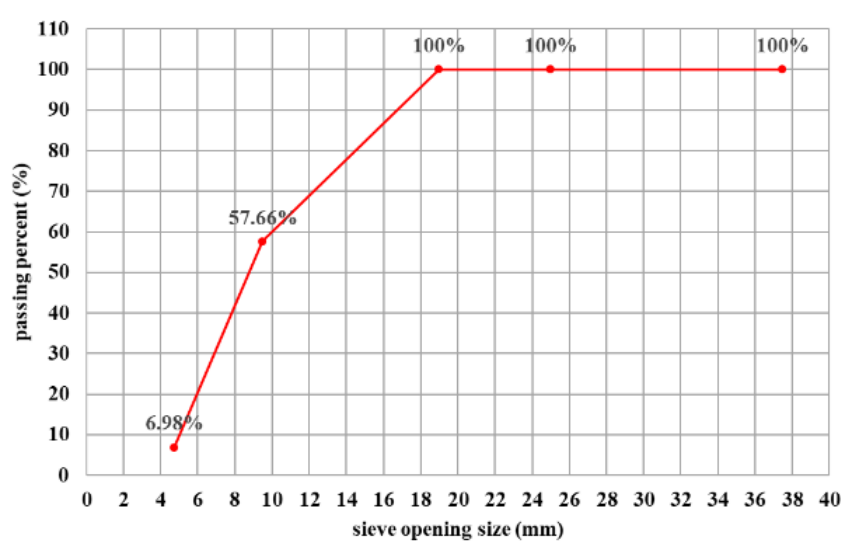

Figure 5. The particle size distribution curve of the coarse aggregates.

The grain size distribution curve for coarse aggregates is presented in Fig. 5, which was used in the saturated surface dry condition and complied with the limits of ASTM C33 [12]. "Sikament $163 \mathrm{M}$ " is the Superplasticizer admixture used in all concrete mixtures to achieve the desired workability, that is, complying with ASTM C494 type (F) [13].

\section{EXPERIMENTAL METHOD}

A total number of four (4) concrete mixtures were designed. The control concrete mixture $\mathrm{C} 0$ was prepared with out nano silica or micro silica. Mixture MS8 was prepared by adding $8 \%$ Micro Silica as a replacement of OPC by the weight. In the mixture MS81, micro silica and Nano-silica were added by $8 \%$ and $1 \%$, respectively. Mixture MS82 was prepared by adding $8 \%$ Micro silica and 2\% Nano-silica, respectively. The proportions of concrete mixes is similar to those used by El-Sharkawi et al. (2018) [11]. The proportions of concrete mixtures are presented in Table 1 where, MS is micro-silica, NS is nano-silica, and SP is superplasticizer.

Figures 6 (a-d) presentes the proceduers of dispersion of nano-silica (NS) particles in the mixing water and preparing of concrete mixes.

Table 1. Proportions of Concrete Mixtures $\left(\mathrm{kg} / \mathrm{m}^{3}\right)$.

\begin{tabular}{llclllll}
\hline Mix. ID & Cement & MS & NS & Sand & Gravel & Water & SP \\
\hline CC0 & 400.0 & - & - & 600 & 1200 & 172 & 9.1 \\
CMS8 & 358.6 & 28.7 & - & 600 & 1200 & 172 & 9.1 \\
CMNS81 & 354.0 & 28.3 & 3.5 & 600 & 1200 & 172 & 9.1 \\
CMNS82 & 349.3 & 27.9 & 7.0 & 600 & 1200 & 172 & 9.1 \\
\hline
\end{tabular}

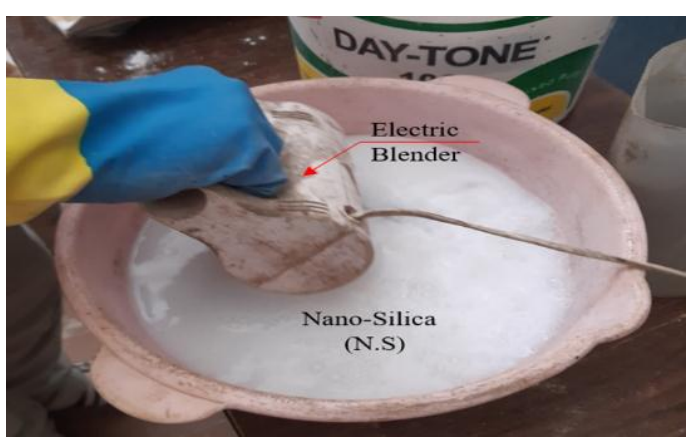

Figure 6 (a). Dispersion of Nano-Silica (NS) particles in the mixing water.

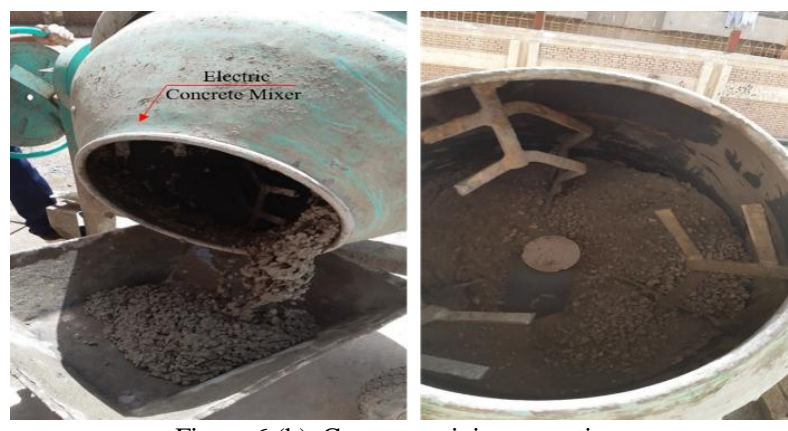

Figure 6 (b). Concrete mixing operation.

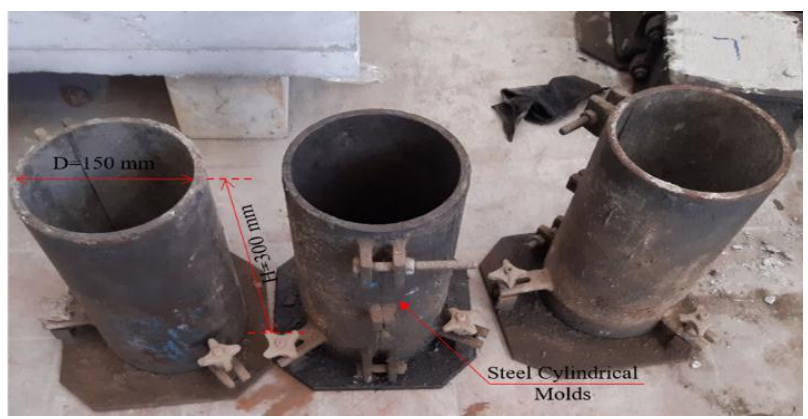

Figure 6 (c). The prepairing of cylindrical concrete specimens.

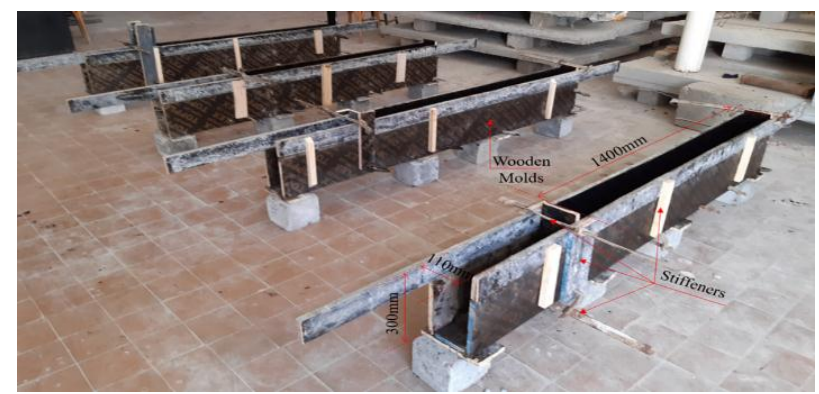

Figure $6(d)$. The prepairing of concrete beams specimens.

For the freshly mixed concrete, the slump test was performed according to ASTM C143 [14], Air content test was performed on all freshly mixed concrete during the casting process according to ASTM C231/C231M-17a [15], and density test was performed according to ASTM C138/C138M17a [16]. Standard cylinder specimens (150x300mm) were prepared for compressive strength test according to ASTM C39/C39 M-21 [17]. Three (3) specimens were prepared from each concrete mixture. The molds were covered with a plastic sheet for 24 hours then the specimens were cured in a water tank at room temperature until testing time. The compressive strength test was carried out 28 days after casting in saturated surface dry status. Figure 7 illustrates the compressive strength test of concrete cylindrical specimens.

To study the behavior of RC beams in shear using the proposed concrete mixes, eight (8) beams (110 x 300 x 1400 $\mathrm{mm}$ ) (Width $\mathrm{x}$ Height $\mathrm{x}$ Length) were cast in this program, which are shown in Fig. 8. All specimens were manufactured and cured with the guidance of BS EN 12390-(1-3) [18]. The beam specimens were designed by ACI 318 [19] to provide the shear failure. 


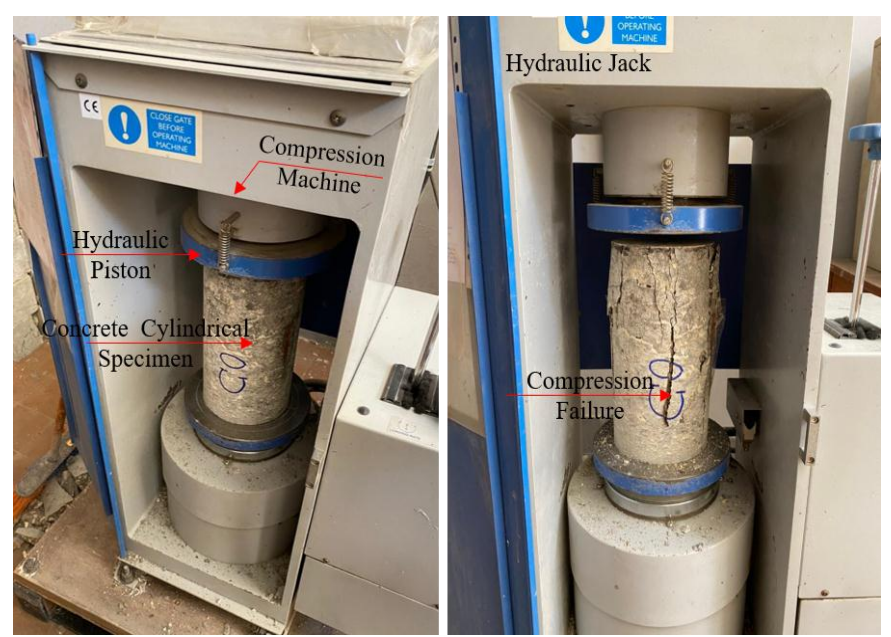

Fig/ure 7. The compressive strength test according to ASTM C39/C39 M-21.

Table 2. The reinforcement used with concrete beams.

\begin{tabular}{|c|c|c|c|c|}
\hline \multirow{2}{*}{$\begin{array}{l}\text { BEAM } \\
\text { ID }\end{array}$} & \multirow{2}{*}{$\begin{array}{l}\text { MIX } \\
\text { ID }\end{array}$} & \multicolumn{3}{|c|}{ Steel Reinforcement } \\
\hline & & Bottom & Top & Stirrups \\
\hline B1 & $\mathrm{CC} 0$ & \multirow{8}{*}{$\begin{array}{l}2-16 \mathrm{~mm} \\
\text { diameter }\end{array}$} & \multirow{8}{*}{$\begin{array}{l}2-10 \mathrm{~mm} \\
\text { diameter }\end{array}$} & - \\
\hline B2 & $\mathrm{CC} 0$ & & & $8 \mathrm{~mm} @ 200 \mathrm{~mm}$ \\
\hline B3 & CMS8 & & & - \\
\hline B4 & CMS8 & & & $8 \mathrm{~mm} @ 200 \mathrm{~mm}$ \\
\hline B5 & CMNS81 & & & - \\
\hline B6 & CMNS81 & & & $8 \mathrm{~mm} @ 200 \mathrm{~mm}$ \\
\hline B7 & CMNS82 & & & - \\
\hline B8 & CMNS82 & & & 8 mm @200mm \\
\hline
\end{tabular}

The beam tension reinforcement was 2-16 mm diameter rebars with $500 \mathrm{MPa}$ yield strength. 2-10 $\mathrm{mm}$ diameter rebars were chosen as compression reinforcement, with 500 Mpa yield strength. Stirrups were $8 \mathrm{~mm}$ diameter spaced at $200 \mathrm{~mm}$ with $240 \mathrm{MPa}$ yield strength used as shear reinforcement in some specimens.

Table 2 presents the reinforcement of each beam. This distribution aimed to enable studying both parameters under consideration and the effect of web reinforcement.

The beams specimens were tested at age of 28 days under four-point bending load over a clear span of $1200 \mathrm{~mm}$ with an overhang length of $100 \mathrm{~mm}$ at each end to provide a development length and prevent bond-slip failure of the flexural reinforcing bars. Figures 9 (a-b) shows the concrete dimensions and reinforcement of beam specimens with and without steel stirrups.

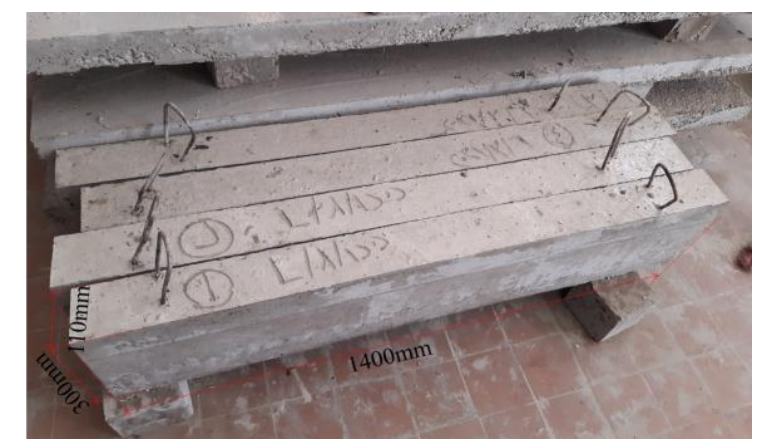

Figure 8 . The reinforced concrete beams specimens after hardening. All beams are $110 \mathrm{~mm}$ wide, $300 \mathrm{~mm}$ deep and $1400 \mathrm{~mm}$ span.

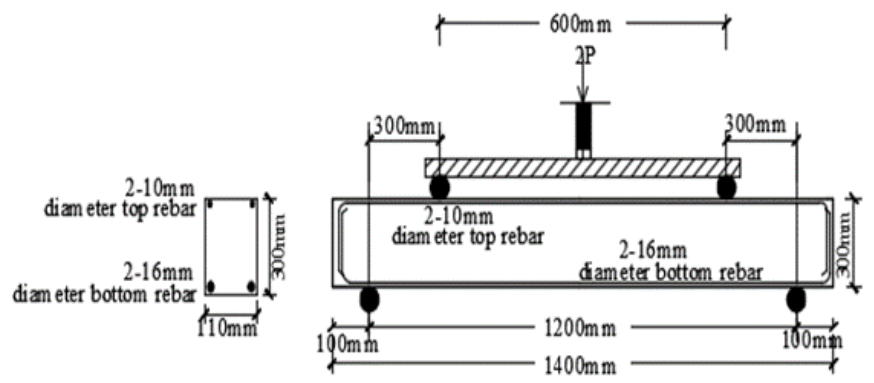

(a). Beams without stirrups.

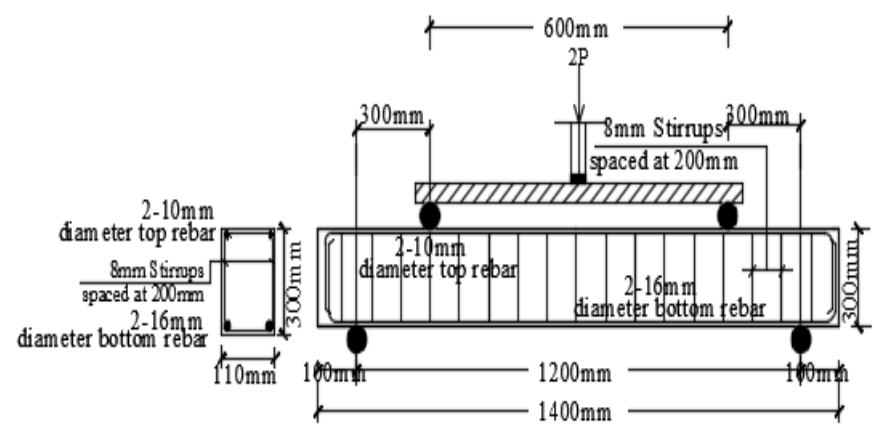

(b). Beams with stirrups.

Figure 9. The reinforced concrete.

To avoid the local failure under the loading, two 5-mm thick rubber sheets were installed under the loading rods and over the supports as well. All beams had the same span-todepth ratio $(\mathrm{a} / \mathrm{d})$ of 1.07 . The load was applied using $700 \mathrm{kN}$ capacity actuator; the load was applied at a displacementcontrolled rate of $0.6 \mathrm{~mm} / \mathrm{min}$ to overcome any accidental problems of the sudden and brittle shear failure.

Linear Variable Differential Transducers (LVDTs) were used to measure the deflection at mid-span and mid-shear span. The loading cell and LVDTs were connected to the data logger to record the results. To measure the shear crack widths at the shear span, a $300 \mathrm{~mm}$ mechanical strain gauge was used. Figure 10 illustrates the testing of beams specimens.

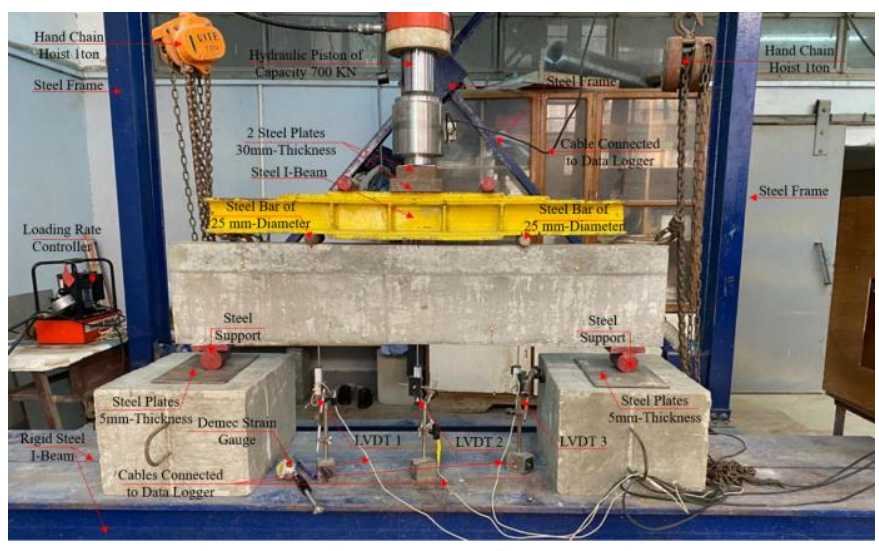

Figure 10. The test setup of beam specimens.

\section{RESULTS AND DISCUSSION}

To investigate the effect of nano and micro silica particles on physical properties for freshly mixed concrete, the slump, 
air content, and density tests are performed. It is opserved that, the addition of nano or micro silica particles decreased the slump and air content of fresh concrete mixture, the slump for concrete mixture with nano-micro silica mixture (CMNS81 and CMNS82) is the lowest slump, $170 \mathrm{~mm}$. On the other hand, the concrete mixture with $2 \% \mathrm{NS}$ and $8 \% \mathrm{MS}$, has the lowest air content, $0.60 \%$. However, the nano or micro silica particles have no any significan effect on concrete density. The tests results on fresh concrete presented in table 3.

Table 4 and Fig. 11 illustrate the results of the compressive strength test for concrete specimens after 28-days of age. All testing was performed for a replicate of 3 specimens. Cylinders with micro and nano silica achieved a strength of 51-56 MPa, compared with $42 \mathrm{MPa}$ of control concrete mix. On the other hand, adding $8 \%$ micro silica only leads to a concrete mix with $48 \mathrm{MPa}$ compressive strength. It is apparent that the inclusion of nano silica in the micro nano silica mixture improved the compressive strength of concrete. The increase in compressive strength using micro silica is significant compared with the control mix. Adding 1\% nano silica in the micro nano silica mixture resulted in an insignificant increase in compressive strength compared with concrete mixes with micro silica only. However, the addition of $2 \%$ nano silica in the micro nano silica mixture resulted in a significant increase in concrete strength compared with concrete mixes with micro silica only.

The enhancement of concrete compressive strength produced by nano-micro silica mixture is due to the high content of Calcium-Silicate-Hydrate cristals $(\mathrm{C}-\mathrm{S}-\mathrm{H})$ produced by the chemical reaction between Nano-micro silica particles and the calcium hydroxide $\mathrm{Ca}(\mathrm{OH}) 2$ or $(\mathrm{CH})$ released by the hydration of Portland cement in the presence of moisture. In addition to the expected enhancement of pore filling mechanism due to using multi particle's sizes, using $2 \% \mathrm{NS}+$ $8 \% \mathrm{MS}$ mixture showed higher microstructural density compared to the case of using either $8 \%$ MS cement replacement ratio separately or control mix.

It can be concluded from the tested beams that using both micro and nano silica particles had a significant enhancement in shear capacity (up to $59 \%$ in beams without steel stirrups and $30 \%$ in beams with steel stirrups).

Table 3. Slump, air content and density of concrete mixtures.

\begin{tabular}{|c|c|c|c|}
\hline \multirow{2}{*}{ Mix ID } & \multicolumn{3}{|c|}{ Test } \\
\cline { 2 - 4 } & Slump $(\mathrm{mm})$ & $\begin{array}{c}\text { Air Content } \\
(\%)\end{array}$ & $\begin{array}{c}\text { Density } \\
\left(\mathrm{kg} / \mathrm{m}^{3}\right)\end{array}$ \\
\hline CC0 (Control) & 190 & 1.50 & 2401.0 \\
\hline CMS8 & 175 & 0.90 & 2407.4 \\
\hline CMNS81 & 170 & 0.80 & 2408.0 \\
\hline CMNS82 & 170 & 0.60 & 2414.1 \\
\hline
\end{tabular}

Table 4. The compressive strength of different concrete specimens at 28 days of age.

\begin{tabular}{|c|c|c|}
\hline $\begin{array}{c}\text { Specimen } \\
\text { ID }\end{array}$ & Concrete Mix & $\begin{array}{c}\text { Average Compressive } \\
\text { Strength (MPa) }\end{array}$ \\
\hline CC0 & Control Mix & 42 \\
\hline CMS8 & Mix with 8\% M.S & 48 \\
\hline CMNS81 & $\begin{array}{c}\text { Mix with 8\% M.S } \\
\text { and 1\% N.S }\end{array}$ \\
\hline CMNS82 & $\begin{array}{c}\text { Mix with 8\% M.S } \\
\text { and 2\% N.S }\end{array}$ \\
\hline
\end{tabular}

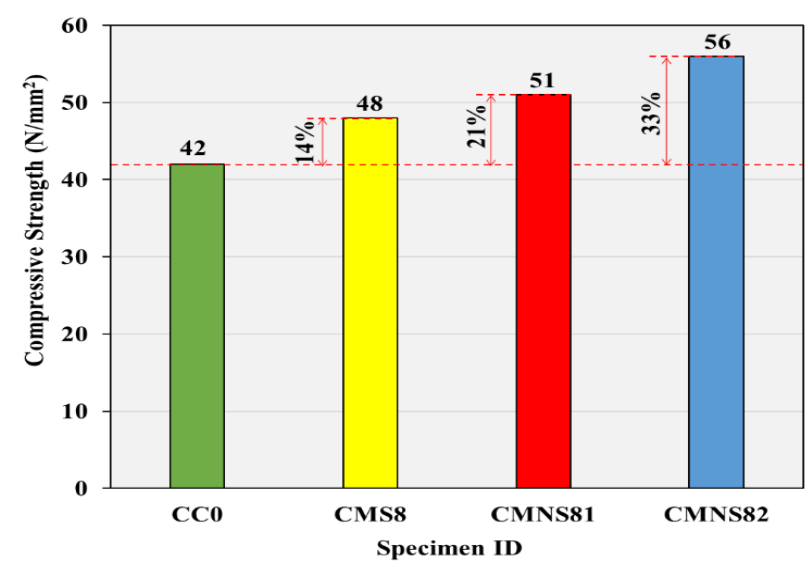

Figure 11. Compressive strength of different concrete specimens at 28 days of age.

The shear behavior of the beams is illustrated and discussed, including shear load carrying capacity, load-deflection response, and applied shear force-to-shear crack width relationships. It is obvious that the tested beam specimens failed in shear as intended. For beams with no steel stirrups, shear failure was brittle and occurred very quickly. The failure in beams with stirrups was slightly slower and took place when the steel stirrups reached their yield strength then, the shear cracks started to widen rapidly as the applied load increased. Finally, a concrete crushing at the top fiber of the beam near the loading point occurred. Table 5 and Figures 12 (a-b) illustrate the shear load carrying capacity for tested beams, B1 to $\mathrm{B} 8$, at 28-days of age.

The cracking of each beam was monitored during each beam testing with emphasis on the shear cracks in the two shear zones of each beam. The crack under consideration herein is the failure shear crack (the critical shear crack). Figure 13 shows the final cracking pattern of the tested beams schematically at failure. The shear failure of reinforced concrete beam specimens occurred at shear span in inclined planes, with inclination angle ranges from $45^{\circ}$ to $47^{\circ}$, which was in good agreement with the method of $45^{\circ}$ truss model for shear analysis [20].

Table 5. The Shear load carrying capacity for tested beams.

\begin{tabular}{|c|c|c|}
\hline $\begin{array}{c}\text { Beam } \\
\text { ID }\end{array}$ & $\begin{array}{c}\text { MIX } \\
\text { ID }\end{array}$ & $\begin{array}{c}\text { Shear-Load Carrying Capacity (kN) at } \\
\text { 28-days age }\end{array}$ \\
\hline B1 & CC0 & 123 \\
\hline B2 & CC0 & 184 \\
\hline B3 & CMS8 & 143 \\
\hline B4 & CMS8 & 193 \\
\hline B5 & CMNS81 & 183 \\
\hline B6 & CMNS81 & 231 \\
\hline B7 & CMNS82 & 196 \\
\hline B8 & CMNS82 & 240 \\
\hline
\end{tabular}




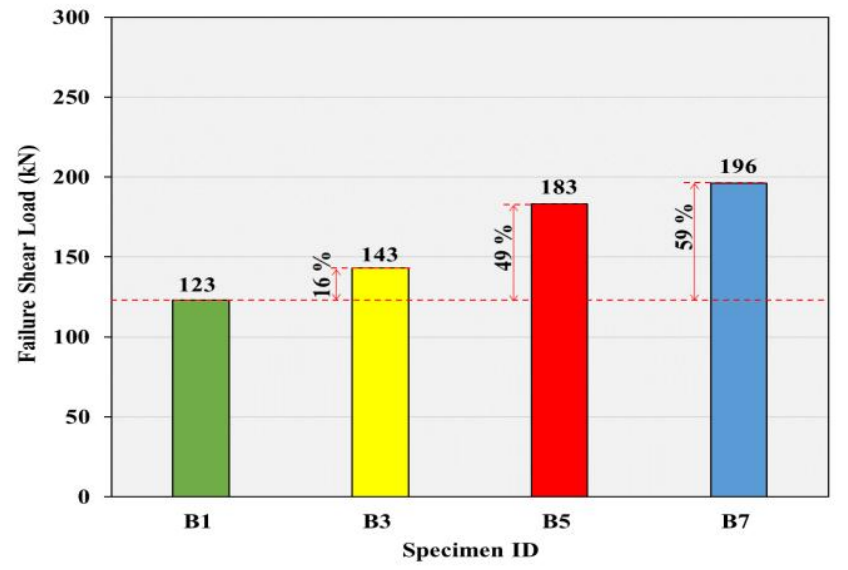

(a). Beams without stirrups.

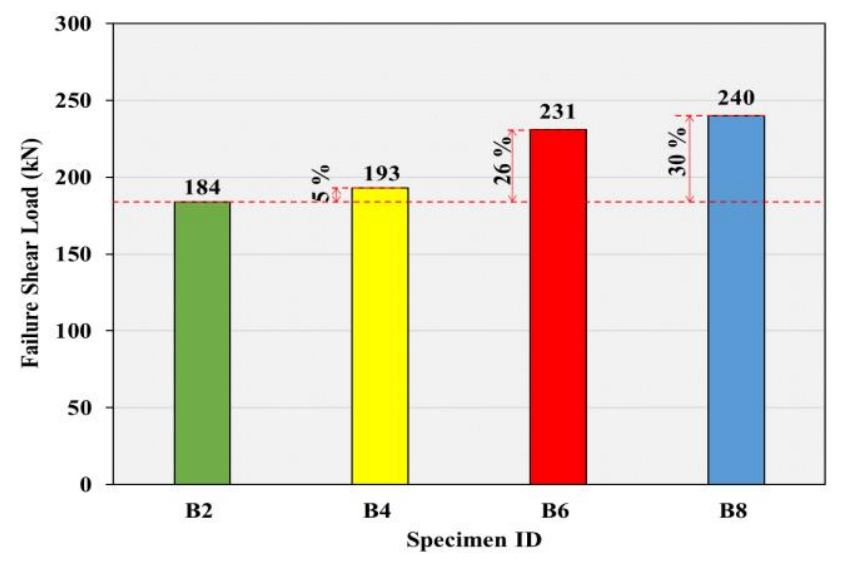

(b). Beams with stirrups.

Figure 12. Shear load carrying capacity.

It is observed that the main difference in final cracking patterns between the tested beams was the number and spacing of diagonal cracks developed in the shear spans. The higher the failure load, the greater the number of induced shear cracks. The tested beams with and without steel stirrups failed at the same location, and the failure plane passed through the midshear span closer to the loading point with an inclined failure plane of the same angle, approximately.

The comparison of applied shear force versus shear crack width relationships for tested beams specimens is illustrated in Fig. 14. For beams without steel stirrups, B1, B3, B5, and B7, the first shear crack onset at shear load ranging from $70 \mathrm{kN}$ to $100 \mathrm{kN}$ with width ranges from $290 \mu \mathrm{m}$ to $400 \mu \mathrm{m}$. The appearance of first shear crack for beams with steel stirrups, $\mathrm{B} 2, \mathrm{~B} 4, \mathrm{~B} 6$, and B8 at shear loads ranges from $60 \mathrm{kN}$ to 116 $\mathrm{kN}$, which have a width ranging from $126 \mu \mathrm{m}$ to $200 \mu \mathrm{m}$. As shear load increases, the shear crack continues to widen, it ranges from $1100 \mu \mathrm{m}$ to $1300 \mu \mathrm{m}$ for beams without steel stirrups and from $1500 \mu \mathrm{m}$ to $2200 \mu \mathrm{m}$ for beams with steel stirrups.

It can be concluded that the inclusion of nano silica - micro nano silica mixture does not seem to have a significant effect on the shear crack width of concrete beams reinforced with steel stirrups. However, incorporating nano silica - micro silica mixture improved the resistance of shear cracking which is attributed to the significance of nano silica on the compressive strength of concrete and thus the tensile strength of concrete that controls shear cracking.
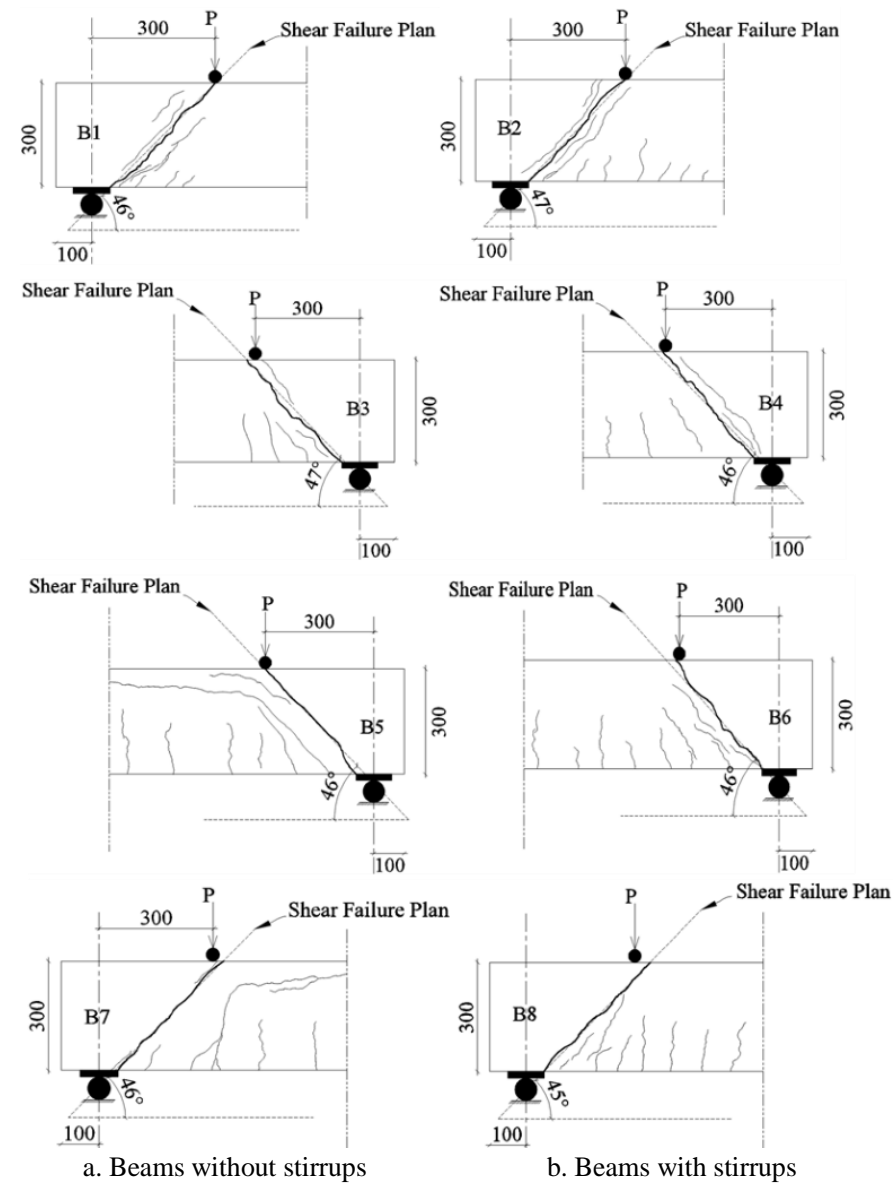

Figure 13. The final cracking pattern at failure for tested concrete beams (left) without stirrups (right) with stirrups.

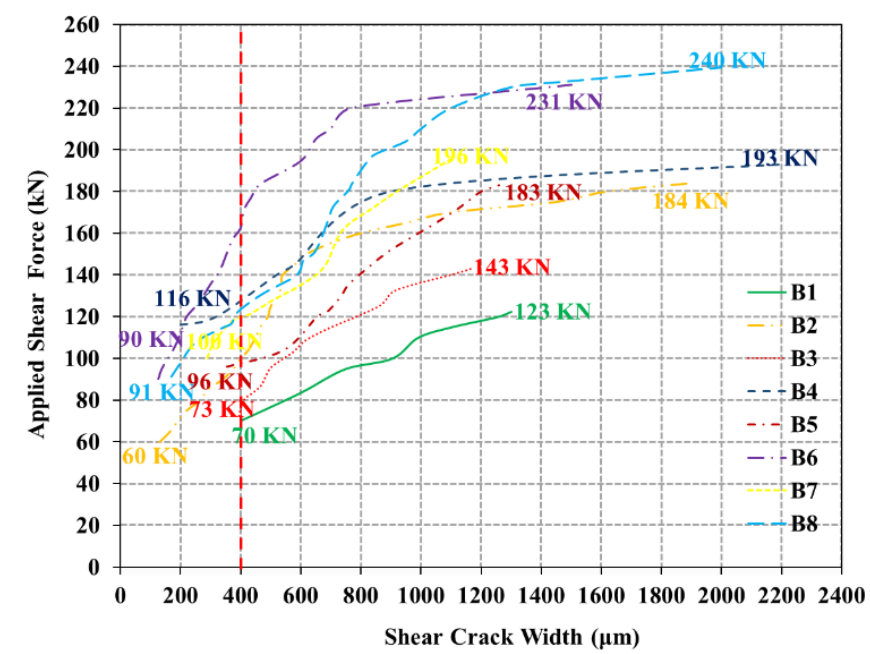

Figure 14. Shear force versus shear crack width in concrete beams.

The modified compression failed theory used to analyze the shear strength components of tested reinforced concrete beams. The Canadian Highway Bridge Design Code, CHBDC, 
CAN/CSA-S6-06 (CSA 2006) [21] was used to Predict the cracking angles, theta $(\theta)$ and the beta $(\beta)$ factor representing the shear contribution by concrete. The nominal shear strength predicted for the tested beams is presented in Table 6 and compared with the experimental observation. The analysis used a value of 1.0 for all material and safety factors.

It can be observed from Table 6 that the shear strength of tested beams reflects an increase in the $\beta$, factor representing the contripution of concrete in shear strength of concrete beams, and no significant change in the cracking angle $\theta$ for the different concrete mixtures. Interestingly, the reinforced concrete beams with concrete mixtures incorporating nanomicro silica mixture have the highest $\beta$ factor values compared with the control concrete beams. The addition of nano-micro silica mixture to concrete mixtures increased the concrete contribution to the shear strength of reinforced concrete beams up to $12 \%$ and $17 \%$ for beams with and without steel stirrups, respectively compared with control specimens. Further research is warranted to understand the reason behind this increase at the microstructural level and to examine the significance of incorporating nano-micro silica on the shear friction of concrete.

All specimens failed in shear prior to reaching their flexural capacity as designed; hence the failure was brittle. This relationship for all beams of the same group is demonstrated in Figures 15 and 16 for mid shear span and mid-span, respectively.

Table 6. The analysis of shear strength for tested beams.

\begin{tabular}{|c|c|c|c|c|c|}
\hline \multirow{2}{*}{ Beam } & \multicolumn{2}{|c|}{ Experimental } & \multicolumn{3}{c|}{ CHBDC (CSA 2006) [21] - MCFT } \\
\cline { 2 - 6 } & $\begin{array}{c}\mathrm{V}_{\text {exp. }} \\
(\mathrm{kN})\end{array}$ & $\begin{array}{c}\theta \\
(\text { degree })\end{array}$ & $\begin{array}{c}\mathrm{V}_{\text {pred. }} \\
(\mathrm{kN})\end{array}$ & $\begin{array}{c}\theta \\
(\text { degree })\end{array}$ & $\beta$ \\
\hline B1 & 123 & 46 & 128 & 46 & 0.284 \\
\hline B2 & 184 & 47 & 154 & 47 & 0.259 \\
\hline B3 & 143 & 47 & 144 & 47 & 0.301 \\
\hline B4 & 193 & 46 & 165 & 46 & 0.267 \\
\hline B5 & 183 & 46 & 160 & 46 & 0.323 \\
\hline B6 & 231 & 46 & 180 & 46 & 0.287 \\
\hline B7 & 196 & 46 & 173 & 46 & 0.333 \\
\hline B8 & 240 & 45 & 190 & 45 & 0.290 \\
\hline
\end{tabular}

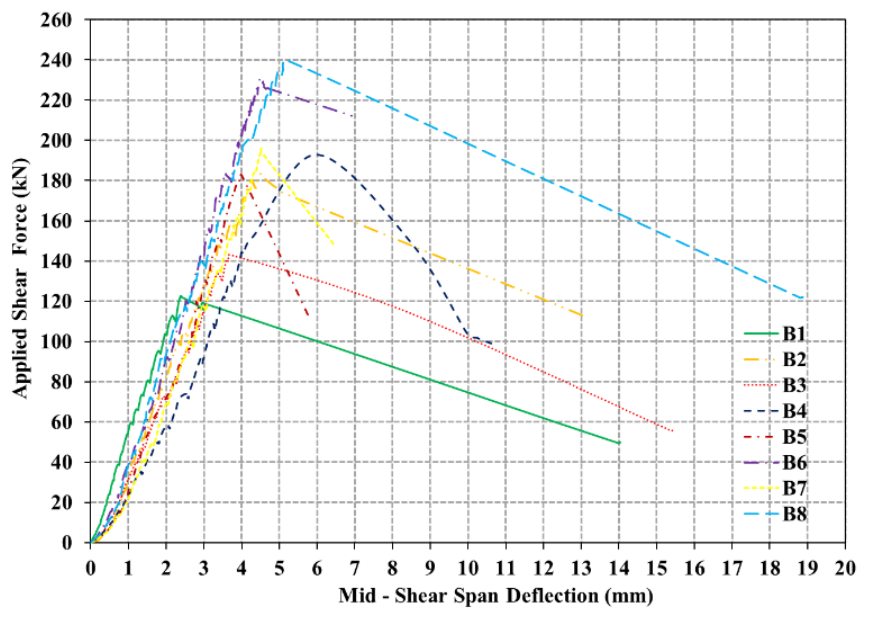

Figure 15. Load-deflection relationship for at Mid-Shear Span.

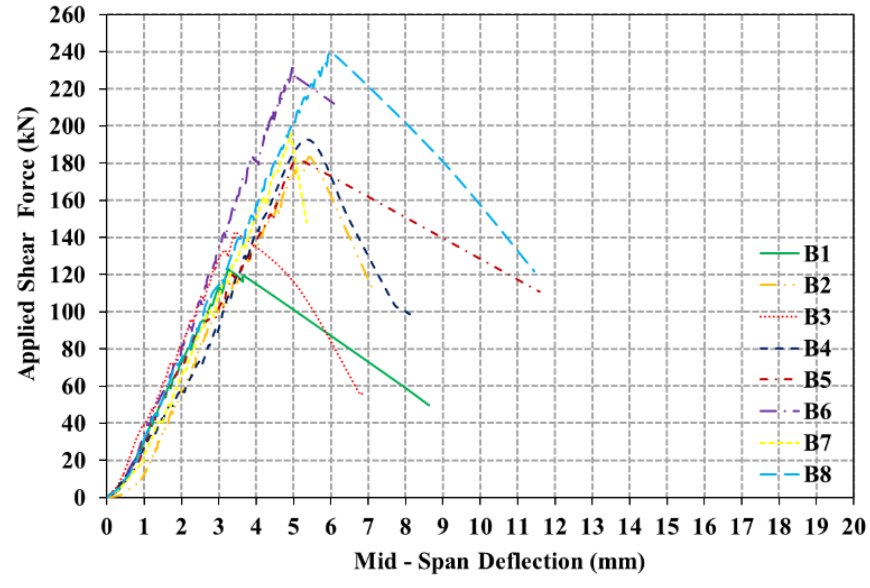

Figure 16. Applied shear force-Deflection relationship at Mid-Span.

\section{CONCLUSIONS}

The nano-micro silica mixture have a significant effect on the physical properties on fresh concrete mixture. The concrete mixture with $2 \%$ nano silica and $8 \%$ micro silica has the lowest slump and air content test compared with the control mix. However, nano-micro silica mixture has no a valuable effect on the density of concrete. The concrete mixtures, CC0, CMS8, CMNS81 and CMNS82 have air content $1.5 \%, 0.90 \%, 0.80 \%$ and $0.60 \%$ respectively. The air content values of freshly mixed concrete can well predict the compressive strength of concrete, where the concrete compressive strength is inversely proportional to its air content.

The addition of $2 \%$ nano silica with $8 \%$ micro silica and $1 \%$ nano silica with $8 \%$ micro silica ,as a partial replacement of ordinary Portland cement, increased the concrete compressive strength by $33 \%$ and $21 \%$, respectively, over the control concrete specimen at the age of 28-days. On the other hand, the addition of micro silica only of proportion $8 \%$ increased the compressive strength of concrete by $14 \%$. Hence, the compressive strength of concrete increased efficiently by the addition of nano micro silica mixture.

For the concrete beams, the shear load carrying capacity is significantly improved by adding nano-micro silica mixture. $2 \%$ nano silica with $8 \%$ micro silica ,as a partial replacement of ordinary Portland cement, seems to be the optimum combination of those examined to enhance the shear strength of concrete beams. The beam specimens without steel stirrups, B3, B5 and B7, are enhanced in shear strength by $16 \%, 49 \%$ and $59 \%$, respectively over the control concrete specimen (B1) at 28-days age. As for the beam specimens with steel stirrups, B4, B6, B8, the shear strength increased by $5 \%, 26 \%, 30 \%$, respectively. The addition of nano-micro silica mixture to concret mixes has not any significant changes on the shear crack width or the behavior of beams in deflection.

The nano or micro silica particles at different proportions showed no significant effect on the shear cracking angles or shear failure location. However, analysis using the modified compression field theory shows that concrete mixtures incorporating nano-micro silica have the highest $\beta$, factor representing the contripution of concrete in shear strength of concrete beams, values compared with the control beams. The addition of $2 \%$ nano-silica with $8 \%$ micro-silica increased $\beta$ factor up to $12 \%$ and $17 \%$ for beams with and without steel 
stirrups, respectively. It is thus apparent that incorporating nano-micro silica can increase the concrete contribution to the shear strength of reinforced concrete beams.

\section{REFERENCES}

[1] Rakesh, K., Renu, M. and Arun, K., Opportunities \& Challenges for use of Nanotechnology in Cement Based Materials, CRRI, New Delhi, 2004.

[2] Khalifa, O., Evaluating the Performance of Portland Cement Based Materials Modified by Pozzolanic Materials and Nano Particles MSc. Thesis, Tanta University, Egypt, 2015.

[3] PCA Committee, Design and Control of Concrete Mixtures, Chapter 3: Fly Ash, Slag, Silica Fume, and Natural Pozzolans. EB001, 2002, pp. 57-72.

[4] Sobolev, K., Development of nano-SiO2 based admixtures for high performance cement-based materials, Progress report, CONACYT, Mexico, 2006.

[5] Biricik, H., Sarier, N., Comparative Study of the Characteristics of Nano Silica, Silica Fume and Fly Ash Incorporated Cement Mortars, Mater. Res. 17 (3), 2014, pp. 570-582.

[6] Abhilash, P.P., Dheeresh, K.N., Bhaskar, S., Rajesh, K. and Veerendra, K., Effect of nano-silica in concrete; a review, Construction and Building Materials, V. 278, 2021.

[7] Silva, J.V., Ismael, R., Carmo, R.N., Lourenço, C., Soldado, E., Costa, $\mathrm{H}$. and Júlio, E., Influence of nano-SiO2 and nano-A12O3 additions on the shear strength and the bending moment capacity of $\mathrm{RC}$ beams, Construction and Building Materials, V. 123, 2016, pp. 35-46.

[8] EN 197-1, Composition, specifications and conformity criteria for common cements, Standard, European Norm, 2011.

[9] ASTM C1240, Standard Specification for Silica Fume Used in Cementitious Mixtures, American Society of Testing Materials, 2015.

[10] HBRC, Housing and Building Research Centre, Materials Engineerin Department, Cairo, Egypt, 2020.

[11] El-Sharkawy, A., Abd-Elaty, M., and Khailfa, O., Synergistic influence of micro-nano silica mixture on durability performance of cementitious materials, Construction and Building Materials journal, V. 164, 2017, pp. 579-588.

[12] ASTM C33, Standard Specification for Concrete Aggregates, American Society of Testing Materials, 2016.

[13] ASTM C494, Standard Specification for Chemical Admixtures for Concrete, American Society of Testing Materials, 2017.

[14] ASTM-International. ASTM C143/C143M-15a, Standard test method for Slump of Hydraulic-Cement Concrete, ASTM International: West Conshohocken, PA, USA, 2015.

[15] ASTM-International. ASTM C231/C231M-17a, Standard Test Method for Air Content of Freshly Mixed Concrete by the Pressure Method, ASTM International: West Conshohocken, PA, USA, 2017.

[16] ASTM-International. ASTM C138/C138M-17a, Standard test method for Density (Unit Weight), Yield, and Air Content (gravimetric) of Concrete, ASTM International: West Conshohocken, PA, USA, 2017.

[17] ASTM-International. ASTM C39/C39 M-21, Standard Test Method for Compressive Strength of Cylindrical Concrete Specimens, ASTM International: West Conshohocken, PA, USA, 2021.

[18] BS EN 12390-(1-3), Testing hardened concrete, British Standard European Norm, 2012.

[19] ACI Committee 318, Reinforced concrete design manual (ACI 31819) Version 19. Berkeley, California: American Concrete Institute, 2019.

[20] ASCE-ACI Committee 445 on Shear and Torsion, (1998), "Recent Approaches to Shear Design of Structural Concrete", ASCE Journal of Structural Engineering, Vol. 124, No.12, December, pp. 1375-1417.

[21] Canadian Standard Association (CSA), (2006), "Canadian Highway Bridge Design Code," CAN/CSA. 